\title{
CNRI Gene is Associated with High Neuroticism and Low Agreeableness and Interacts with Recent Negative Life Events to Predict Current Depressive Symptoms
}

\author{
Gabriella Juhasz*,', Diana Chase', Emma Pegg', Darragh Downey', Zoltan G Toth², Kathryn Stones', \\ Hazel Platt ${ }^{3}$, Krisztina Mekli ${ }^{1,3,4}$, Antony Payton ${ }^{3}$, Rebecca Elliott', Ian M Anderson' and JF William Deakin' \\ 'Neuroscience and Psychiatry Unit, School of Community Based Medicine, Faculty of Medical and Human Sciences, University of Manchester, \\ Manchester, UK; ${ }^{2}$ Faculty of Life Sciences, University of Manchester, Manchester, UK; ${ }^{3}$ Centre for Integrated Genomic Medical Research, School \\ of Translational Medicine, Faculty of Medical and Human Sciences, University of Manchester, Manchester, UK; ${ }^{4}$ Department of Pharmacology \\ and Pharmacotherapy, Semmelweis University, Budapest, Hungary
}

\begin{abstract}
Cannabinoid receptor I (CBI) gene (CNRI) knockout mice are prone to develop anhedonic and helpless behavior after chronic mild stress. In humans, the CBI antagonist rimonabant increases the risk of depressed mood disorders and anxiety. These studies suggest the hypothesis that genetic variation in CBI receptor function influences the risk of depression in humans in response to stressful life events. In a population sample $(n=1269)$, we obtained questionnaire measures of personality (Big Five Inventory), depression and anxiety (Brief Symptom Inventory), and life events. The CNRI gene was covered by 10 SNPs located throughout the gene to determine haplotypic association. Variations in the CNRI gene were significantly associated with a high neuroticism and low agreeableness phenotype (explained variance 1.5 and 2.5\%, respectively). Epistasis analysis of the SNPs showed that the previously reported functional $5^{\prime}$ end of the CNRI gene significantly interacts with the $3^{\prime}$ end in these phenotypes. Furthermore, current depression scores significantly associated with CNRI haplotypes but this effect diminished after covariation for recent life events, suggesting a gene $\times$ environment interaction. Indeed, rs7766029 showed highly significant interaction between recent negative life events and depression scores. The results represent the first evidence in humans that the CNRI gene is a risk factor for depression-and probably also for co-morbid psychiatric conditions such as substance use disorders - through a high neuroticism and low agreeableness phenotype. This study also suggests that the CNRI gene influences vulnerability to recent psychosocial adversity to produce current symptoms of depression. Neuropsychopharmacology (2009) 34, 2019-2027; doi:I0.1038/npp.2009.19; published online 25 February 2009
\end{abstract}

Keywords: CNRI; haplotype; personality; depression; epistasis; gene $\times$ environment interaction

\section{INTRODUCTION}

Accumulating evidence suggests that the endocannabinoid (eCB) system plays an important role in the etiology of depression through control of emotional behavior (Martin et al, 2002; Hill and Gorzalka, 2005a; Vinod and Hungund, 2006; Serra and Fratta, 2007). In humans, the acute effects of cannabis include euphoria and relaxation, but early and chronic use has been associated with increased risk of psychotic illness and deterioration of bipolar disorder (Hall and Solowij, 1998; Ashton et al, 2005). Rimonabant, a cannabinoid receptor 1 (CB1) antagonist, administered to humans as a weight-loss drug, has been shown to increase the risk of depressed mood disorder, and anxiety even

\footnotetext{
*Correspondence: Dr G Juhasz, Neuroscience and Psychiatry Unit, School of Community Based Medicine, Faculty of Medical and Human Sciences, University of Manchester, Stopford Building, Oxford Road, Manchester MI 3 9PT, UK, E-mail: gabriella.juhasz@manchester.ac.uk Received 25 November 2008; revised 12 January 2009; accepted 27 January 2009
}

though depressed mood in the history was an exclusion criteria in these trials (Christensen et al, 2007). In animal studies, anxiogenic-like or anxiolytic effects of cannabinoids depend on the strain, the behavioral test used, and the drug dosage (Martin et al, 2002; Haller et al, 2004a). Rimonabant produces antidepressant-like effects in different species and models (Witkin et al, 2005) but an eCB uptake inhibitor (AM404) and a potent CB1 receptor agonist (HU-210) also elicit antidepressant-like effects in the forced swim test in rats (Hill and Gorzalka, 2005b). Animals with genetic deletion of the CB1 receptor (CB1-I-) exhibit anxiogenic-like responses in different behavioral models (Haller et al, 2004a) and a tendency to develop a depressive-like state (anhedonia) during the exposure to the chronic unpredictable mild stress paradigm (Martin et al, 2002; Valverde et al, 2005). Thus, taken as a whole, the current evidence supports the theory that reduction in CB1 receptor signaling induces increased anxiety and depression-like behavior (Hill and Gorzalka, 2005a). 
The human CB1 receptor gene (CNR1) is located at chromosome $6 \mathrm{q} 14-15$, but the exact structure of the gene and its effect on the CB1 receptor function are still unclear (Zhang et al, 2004). This genetic region has been linked to schizophrenia (Levinson et al, 2000; Leroy et al, 2001), but this has not been replicated, although recently the CNR1 gene has been associated with specific symptoms or with non-responder status for antipsychotic drugs rather than with schizophrenia as a disorder (Chavarria-Siles et al, 2008; Hamdani et al, 2008). There are more convincing results on the association of the CNR1 gene and substance abuse disorders (Zhang et al, 2004; Zuo et al, 2007; Chen et al, 2008), although there is a negative replication study (Herman et al, 2006). Regarding depression, two studies with significantly smaller sample sizes failed to find any association with depression using the (AAT) ${ }_{n}$ polymorphism (Barrero et al, 2005; Tsai et al, 2001), although the former found that a significant association emerged when only the depressed patients with Parkinson's disease were considered (Barrero et al, 2005).

Given that the CNR1 gene has been implicated in a broad spectrum of psychiatric disorders, it is plausible that it affects dimensions of psychopathology (eg, specific personality factors) that are risk factors for these disorders (Widiger and Sankis, 2000; Khan et al, 2005). Twin studies have demonstrated that personality factors are highly influenced by genes. Using measures of Big Five-factor models of personality, the heritability has been estimated as follows: extraversion 0.54 , agreeableness $0.42-0.52$, conscientiousness 0.40 0.49 , neuroticism 0.48-0.58, and openness 0.52-0.57 (Bouchard and McGue, 2003). Furthermore, twin studies have also suggested that the correlations between personality factors and psychiatric disorders are mainly due to shared genetic factors (Kendler et al, 2006; Fanous and Kendler, 2005). However, we could not find a systematic investigation of the association between the CNR1 gene and different personality factors. Impulsivity, which is one facet of neuroticism, has been associated with polymorphisms in the region of the CNR1 gene in an Indian population (Ehlers et al, 2007). Furthermore, two recent studies demonstrated association between striatal response to happy faces and variations of the CNR1 gene and suggested that this gene represents a risk factor for depression through subcortical hypo-responsiveness to social reward stimuli (Chakrabarti et al, 2006; Domschke et al, 2008).

We hypothesized that the CNR1 gene influences personality factors that predispose to specific psychiatric conditions, especially anxiety and depressive symptoms. Most of the animal studies suggest that stress plays crucial role in the effects of the eCB system, so we also investigated the role of adverse life events. We used a population study design with independent individuals and applied haplotypic association analysis to investigate the effect of the CNR1 gene on these phenotypes.

\section{MATERIALS AND METHODS}

\section{Subjects}

Subjects aged 18-60 years predominantly from Greater Manchester, UK, were recruited through general practices and the NewMood website (http://www.newmood.co.uk).
Almost 4500 packs were sent out to individuals on two GP practice lists in the Manchester area, 30\% of people responded, and about half of these agreed to participate. The NewMood website was launched in August 2005 and almost 2000 information/questionnaire packs were sent out to people enquiring about the study through the website and over $50 \%$ of those participated. Altogether more than 2000 people completed and returned the NewMood questionnaire (39\% through general practices and 61\% through NewMood website). Of the sample, $92 \%$ were white, $68 \%$ were women (which reflects the gender ratio of people with depression), $48 \%$ had a history of depression (28\% in the last year), $40 \%$ had had antidepressant treatment in the past, $35 \%$ had a family history of depression, and $84 \%$ were willing to give DNA.

Participants who returned the signed consent form to provide DNA $(n=1679)$ were then sent a genetic sampling kit. Of these subjects, $n=1520$ returned the kit (35\% from general practices and $65 \%$ from NewMood website). Women (78 vs $71 \%$ of men; $p=0.001$ ) and those who had a history of depression ( $55 v s 42 \%$ of those who reported no depression in the past; $p<0.001$ ) were more likely to send a DNA sample.

We excluded those reporting manic or hypomanic episodes, psychotic symptoms, obsessive-compulsive disorder and those of non-Caucasian origin, but we did not exclude those with a self-reported history of depression or any other anxiety disorder, or substance misuse (all information based on background questionnaire data); thus 1269 participants were included in the analysis. Population details are shown in Table 1.

This study was approved by the local ethics committees and was carried out in accordance with the Declaration of Helsinki. All participants provided written informed consent.

\section{Questionnaires}

We used brief standard questionnaires that were easy for participants to complete and return to us by post. The booklet included questions covering background information (age, ethnicity, and family circumstances), personal and family psychiatric history, and questionnaires covering current mood and anxiety, personality, life events, and childhood trauma.

To assess personality, we used the Big Five Inventory (BFI-44) (John and Srivastava, 1999). For analysis, BFI factor scores were calculated using a continuous weighted dimension score (sum of items scored divided by the number of items completed). Although the NEO PI-R (Costa and McCrae, 1992) is the best validated Big Five questionnaire battery, the BFI-44 Inventory has the advantage of being short, easy to understand, and shows a high crossinstrument convergent validity correlations with other fivefactor personality questionnaires (eg with $\mathrm{NEO}$, mean $r=0.73$ ) (John and Srivastava, 1999). In total, 142 of our participants filled out both the NEO PI-R and BFI-44 questionnaires for validation purposes and the results showed highly significant $(p<0.001)$ correlations between the two instruments (Pearson's correlation: extraversion $R=0.79 ; \quad$ agreeableness $\quad R=0.59 ; \quad$ conscientiousness $R=0.75$; neuroticism $R=0.81$; and openness $R=0.66$ ). 
Table I Population Details for Those who Fulfilled the Inclusion Criteria for the Study $(n=1269)$

\begin{tabular}{lc}
\hline Demographics & \\
Sex & \\
$\quad$ Women & $883(70 \%)$ \\
$\quad$ Men & $386(30 \%)$ \\
$\quad$ Age (years) (mean \pm SEM) & $34.04 \pm 0.28$ \\
& \\
Personal psychiatric history & \\
Reported depression & $676(53 \%)$ \\
$\quad$ Single episode & $181(14 \%)$ \\
$\quad$ Recurrent episodes & $495(39 \%)$ \\
Reported suicide & $190(15 \%)$ \\
Reported anxiety & $368(29 \%)$ \\
Reported substance use disorder & $85(7 \%)$ \\
& \\
Family psychiatric history & \\
Reported depression in immediate blood relatives & $449(35 \%)$ \\
& \\
Personality scores (range I-5) & \\
BFI extraversion (mean \pm SEM) & $3.22 \pm 0.03$ \\
BFI agreeableness (mean \pm SEM) & $3.78 \pm 0.02$ \\
BFI conscientiousness (mean \pm SEM) & $3.66 \pm 0.02$ \\
BFI neuroticism (mean \pm SEM) & $3.31 \pm 0.03$ \\
BFI openness (mean \pm SEM) & $3.63 \pm 0.02$ \\
Symptom scores (range 0-4) & \\
BSI depression (mean \pm SEM) & \\
BSI anxiety (mean \pm SEM) & \\
Adversities & $.03 \pm 0.03 \pm 0.03$ \\
Recent negative life events (mean \pm SEM) \\
Childhood adversity (mean \pm SEM) & \\
\hline
\end{tabular}

BFI, Big Five Inventory; BSI, Brief Symptom Inventory.

Depressive symptoms were measured using the depression subscale plus additional items, and anxiety symptoms using the anxiety subscale from the 53-item Brief Symptom Inventory (BSI) (Derogatis, 1993). A continuous weighted dimension score (sum of item scores on the dimension divided by the number of items completed) was calculated. Mood and anxiety symptoms of 140 participants were also rated by independent trained investigators using the Montgomery Asberg Depression Rating Scale (Montgomery and Asberg, 1979) and the Clinical Anxiety Scale (Snaith et al, 1982). The results showed highly significant $(p<0.001)$ correlations between the self-reported symptom scores and the independent ratings (Pearson's correlation: depression $R=0.79$; anxiety $R=0.80$ ) in our population.

The recent negative life events questionnaire was adapted from the list of life threatening experiences (Brugha et al, 1985) and asked participants to identify negative life events related to intimate relationships, financial difficulties, illnesses/injuries, and network problems occurring in the last year. The sum of life event items was used in the analysis.
Childhood adversity questions related to emotional and physical abuse, and emotional and physical neglect were derived from the Childhood Trauma Questionnaire (Bernstein et al, 1994). An additional question asked about parental loss during childhood. The sum of item scores was used in the analysis.

\section{Genotyping}

Buccal mucosa cells were collected using cytology brush (Cytobrush plus C0012; Durbin PLC) and 15-ml plastic tube containing $2.0 \mathrm{ml}$ of collection buffer. Genomic DNA was extracted according to a protocol suggested by Freeman et al (2003).

HaploView software package (http://www.broad.mit.edu/ personal/jcbarret/haploview/) was employed to identify haplotype tag SNPs (htSNP; minimum pairwise correlation $\left(r^{2}\right)$ to select htSNPs was 0.8) (Barrett et al, 2005; Gabriel et al, 2002) based on the AFD_EUR_PANEL (AFD_EUR_18MAY-2004) population data of PERLEGEN (http://genome. perlegen.com/) (Hinds et al, 2005) and the CEPH population data of the International HapMap Project (http:// www.hapmap.org; Phase I. June 2005). Previously identified possibly functional htSNPs in the $5^{\prime}$ direction from the CNR1 gene were also examined (Zhang et al, 2004).

The chosen SNPs were genotyped using the Sequenom ${ }^{\circledR}$ MassARRAY technology (Sequenom, San Diego). The Iplex $^{\mathrm{TM}}$ assay was followed according to the manufacturer's instructions (http://www.sequenom.com) using $25 \mathrm{ng}$ of DNA. Genotyping was blinded with regard to phenotype. All laboratory work was performed under the ISO 9001:2000 quality management requirements.

\section{Statistical Analysis}

PLINK v1.04 (http://pngu.mgh.harvard.edu/purcell/plink/) was used for testing the association of different genetic models (dominant, recessive, and additive; linear regression model covariation with age and sex), interactions between htSNPs (epistasis, linear regression model based on allele dosage for tested SNPs), and with life events (linear regression model, covariation with age and sex). Quanto 1.2 version (http://hydra.usc.edu/gxe) was employed to calculate the power of the recruited populations. HardyWeinberg and haplotype analyses were performed using HelixTree $^{\mathrm{TM}}$ 6.4.1 (Golden Helix, USA).

For haplotypic association analysis, we used haplotype trend regression. Only haplotypes with a frequency greater than $5 \%$ were used in the analysis. In all cases, data were adjusted for age and sex. We used linear regression in HelixTree to identify variance in the dependent variable explained by age and sex (the 'reduced model'). We then determined whether adding haplotype frequencies to the model (now the 'full model') explained significantly more variance than the reduced model using a variance ratio F-test. To remove the influence of multiple testing, we used a permutation test, randomly grouping the sample 10000 times. The permutated $p$-values were the fraction of permutated tests that gave an improved $p$-value.

Bonferroni correction assumes independent outcome variables and this assumption is not true of personality factors and symptoms (depression and anxiety); therefore, 
this method unnecessarily increases stringency (Westfall and Young, 1993). Thus, we used false discovery rate (FDR) calculation at a level of 5\% (Qvalue: http://genomics. princeton.edu/storeylab/qvalue/) to adjust $p$-values according to the number of hypothesis tested (Storey and Tibshirani, 2003). We report $q$-value, which is a measure of significance of each test of many tests performed simultaneously.

\section{RESULTS}

The CNR1 gene identified from the current National Center for Biotechnology Information (NCBI, March 2007) database was covered by seven htSNPs; in addition, we genotyped three reported SNPs located $5^{\prime}$ from the gene (see Figure 1). The latter SNPs have a possible effect on the mRNA expression of this gene (Zhang et al, 2004). All of the genotyped SNPs were in Hardy-Weinberg equilibrium. Allele and genotype frequencies can be seen in Supplementary Table S1. On the basis of the method published by Gabriel et al (2002), we identified two blocks of linkage disequilibrium (LD; haploblock 1: rs806379, rs1535255, and rs2023239; haploblock 2: rs806369, rs1049353, rs4707436, rs12720071, rs806368, and rs806366), whereas rs7766029 just partially belonged to the second haploblock (for LD data, see Supplementary Table S2). This haplotype structure is in close agreement with the results previously reported on the European American population (Zuo et al, 2007).

\section{Single Marker Association with Personality and Symptoms}

Detailed single marker association data (additive (add), dominant (dom), and recessive (rec) model) can be seen in

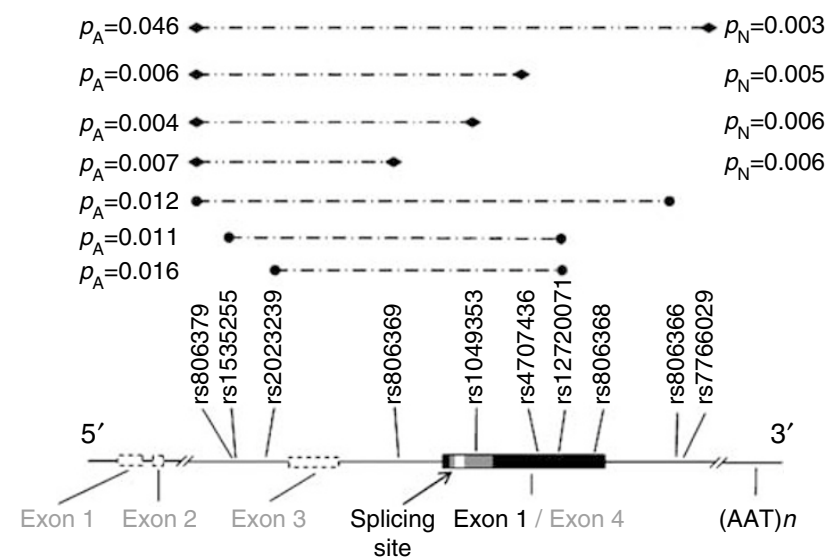

Figure I Schematic figure of the CNRI gene and the position of the genotyped SNPs. Exon numbers in gray are proposed by Zhang et al (2004). The black bar represents the exonic region according to the National Center for Biotechnology Information (NCBI, March 2007) and the University of California at Santa Cruz Browser. The gray region within the black bar corresponds to the coding region and the splicing site is in white. Dashed lines above the rs numbers refer to the significant epistasis between the two haploblocks; $p$-values represented raw $p$ data without correction for multiple testing. ( $p_{A}$ : significant epistasis $p$-values on agreeableness; $p_{N}$ : significant epistasis $p$-values on neuroticism; : relevant SNP pairs in the epistasis calculation that showed significant $p$-values on both phenotypes; : relevant SNP pairs in the epistasis calculation that showed significant $p$-values only on agreeableness).
Supplementary Table S3. In summary, rs1535255 G allele $\left(p_{\text {rec }}=0.023\right)$, rs $2023239 \mathrm{C}$ allele $\left(p_{\text {rec }}=0.046\right)$, and rs806366 $\mathrm{C}$ allele $\left(p_{\text {add }}=0.024\right.$ and $\left.p_{\text {dom }}=0.009\right)$ showed significant positive association with agreeableness; rs4707436 A allele negatively associated with conscientiousness $\left(p_{\text {rec }}=0.043\right)$; neuroticism positively associated with rs 1049353 A allele $\left(p_{\text {add }}=0.042\right.$ and $\left.p_{\text {dom }}=0.039\right)$ and negatively associated with rs806366 C allele ( $p_{\mathrm{add}}=0.017$ and $\left.p_{\mathrm{dom}}=0.038\right)$; and openness negatively associated with rs806368 $\mathrm{C}$ allele $\left(p_{\text {dom }}=0.044\right)$ as did $\operatorname{rs} 7766029 \mathrm{~T}$ allele $\left(p_{\text {dom }}=0.040\right)$. Finally, rs806369 $\mathrm{T}$ allele showed negative association with depression $\left(p_{\text {rec }}=0.038\right)$ and positive association with anxiety $\left(p_{\text {dom }}=0.019\right)$, as did rs7766029 T allele $\left(p_{\text {dom }}=0.038\right)$. All of the reported $p$-values are nominal significance values and none of them survived correction for multiple testing.

For a continuous trait such as neuroticism, using an independent individual study design and assuming a linear model relating the phenotype to genotype, we would require 1045 individuals to detect a polymorphism (with an allele frequency $>10 \%$ ) that explained $1 \%$ of the variance of the trait at the $5 \%$ two-tailed significance level with $90 \%$ power. As we included 1269 participants, our study was adequately powered.

\section{Haplotypic Association with Personality}

Haplotype trend regression showed significant association with neuroticism $(p=0.0043)$ and agreeableness $(p=0.00003$; see Table 2). This association remained significant after permutation and FDR correction (neuroticism: $q=0.0025$ and agreeableness: $q=0.0002$ ). The variations in the CNR1 gene explained $2.5 \%$ variance in agreeableness and $1.5 \%$ variance in neuroticism.

\section{SNP $\times$ SNP Interaction (Epistasis) in Relation to Neuroticism and Agreeableness}

Previously, Zhang et al (2004) showed that haplotypic combination of rs806379, rs1535255, and rs2023239 influenced the expression of CNR1 mRNA. In our study, we tested the hypothesis that the effects of SNPs in the $5^{\prime}$ end haploblock 1 can be modified by the SNPs in the haploblock 2. Indeed, in our study, rs806379 showed significant epistasis with several SNPs on both neuroticism and agreeableness after covariation for age and sex, whereas rs1535255 and rs2023239 showed significant epistasis on agreeableness (Figure 1). Results where $p<0.04$ remained significant after FDR correction for multiple testing.

\section{Haplotypic Association with Depressive and Anxiety Symptoms}

Using haplotypic trend regression, with age and sex as covariates, depressive symptoms were significantly associated with CNR1 haplotypes (explained variance $1.1 \%$, $p=0.037$, permutated $p=0.039$, FDR $q=0.018$; Table 3 ). Figure 2 shows significant haplotypic effects on depression scores, neuroticism, and agreeableness. There was no significant haplotypic association with anxiety symptoms (explained variance $0.7 \%, p=0.281$; Table 3 ). 
Table 2 Haplotypic Trend Regression Results for Personality Factors Measured by the Big Five Inventory (BFI)

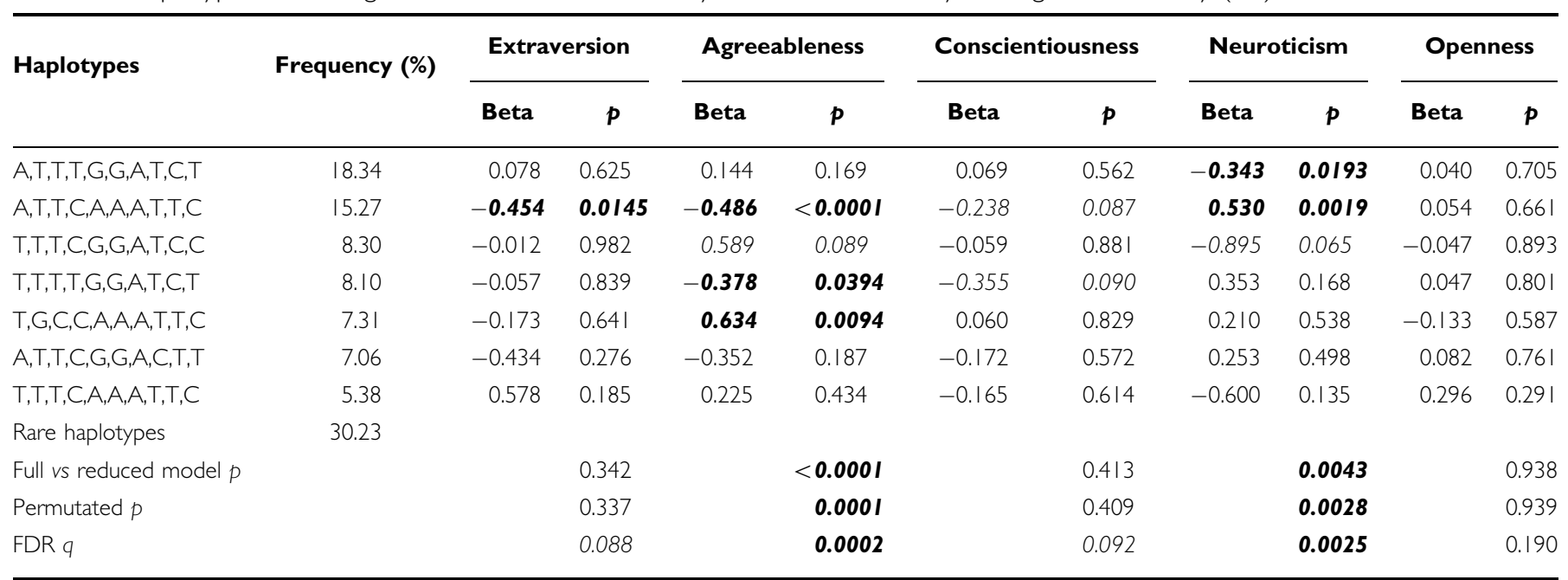

FDR q, false discovery rate significance value.

Age and sex were covariates in all calculations and the order of the htSNPs in the haplotypes corresponds to the SNP order in Figure I.

Bold values indicate significant results $(p<0.05)$, italic values indicate trends $(0.05<p<0.0$ I).

Table 3 Haplotypic Trend Regression Results for Symptom Scores Measured by the Brief Symptom Inventory (BSI)

\begin{tabular}{|c|c|c|c|c|c|c|c|c|c|}
\hline \multirow{2}{*}{ Haplotypes } & \multirow{2}{*}{ Frequency (\%) } & \multicolumn{2}{|c|}{ Anxiety } & \multicolumn{2}{|c|}{ Depression } & \multicolumn{2}{|c|}{ Depression $^{\mathbf{a}}$} & \multicolumn{2}{|c|}{ Depression $^{\text {b }}$} \\
\hline & & Beta & $p$ & Beta & $p$ & Beta & $p$ & Beta & $p$ \\
\hline $\mathrm{A}, \mathrm{T}, \mathrm{T}, \mathrm{C}, \mathrm{A}, \mathrm{A}, \mathrm{A}, \mathrm{T}, \mathrm{T}, \mathrm{C}$ & | 5.27 & 0.250 & 0.169 & 0.403 & 0.037 & 0.339 & 0.071 & 0.456 & 0.010 \\
\hline T,T,T,C,G,G,A,T,C,C & 8.30 & -0.781 & 0.131 & -0.398 & 0.467 & -0.365 & 0.493 & -0.321 & 0.525 \\
\hline $\mathrm{A}, \mathrm{T}, \mathrm{T}, \mathrm{C}, \mathrm{G}, \mathrm{G}, \mathrm{A}, \mathrm{C}, \mathrm{T}, \mathrm{T}$ & 7.06 & -0.058 & 0.884 & 0.129 & 0.761 & 0.208 & 0.612 & 0.011 & 0.977 \\
\hline T,T,T,C,A,A,A,T,T,C & 5.38 & -0.234 & 0.585 & -0.366 & 0.419 & -0.286 & 0.516 & -0.153 & 0.713 \\
\hline Rare haplotypes & 30.23 & & & & & & & & \\
\hline Full vs reduced model $p$ & & & 0.281 & & 0.037 & & 0.071 & & 0.012 \\
\hline Permutated $p$ & & & 0.278 & & 0.039 & & 0.074 & & 0.012 \\
\hline
\end{tabular}

FDR q, false discovery rate significance value.

${ }^{a}$ After covariation for recent negative life events $(p<0.001)$.

${ }^{\mathrm{b}}$ After covariation for childhood adversity $(p<0.001)$.

Age and sex were covariates in all calculations and the order of the htSNPs in the haplotypes corresponds to the SNP order in Figure I.

Bold values indicate significant results $(p<0.05)$, italic values indicate trends $(0.05<p<0.01)$.

The magnitude of the haplotypic effect on depression scores remained unchanged after excluding subjects with reported substance use disorder (explained variance 1.3\%, $p=0.026$, permutated $p=0.027$ ) and with reported suicide attempt (explained variance $1.3 \%, p=0.047$, permutated $p=0.053)$.

\section{CNR1 $\times$ Environment Interaction in Relation to Depression Scores}

The significant CNR1 haplotype association with depressive symptoms became nonsignificant (explained variance $0.9 \%$, $p=0.071$, permutated $p=0.074$; Table 3 ) after controlling for recent negative life events scores. It is possible that the
CNR1 gene might have an effect either on experiencing repeated negative life events through personality-dependent life choices or through modifying the interpretation of a specific life event (McGue and Bouchard, 1998; Bouchard and McGue, 2003).

Indeed, rs7766029 showed highly significant interaction with recent negative life events on depression scores $\left(p_{\text {add }}=0.0004, p_{\text {rec }}=0.0007\right)$, which remained significant after FDR correction for multiple testing $\left(q_{\text {add }}=0.004\right.$, $q_{\text {rec }}=0.004$; age, sex, and recent negative life events were covariates in the analysis; Figure 3). Two other SNPs also showed tendencies to interact with recent negative life events on depression scores ( $r 806369 \quad p_{\text {dom }}=0.028$; rs1049353 $\left.p_{\text {dom }}=0.052\right)$, but these associations did not 


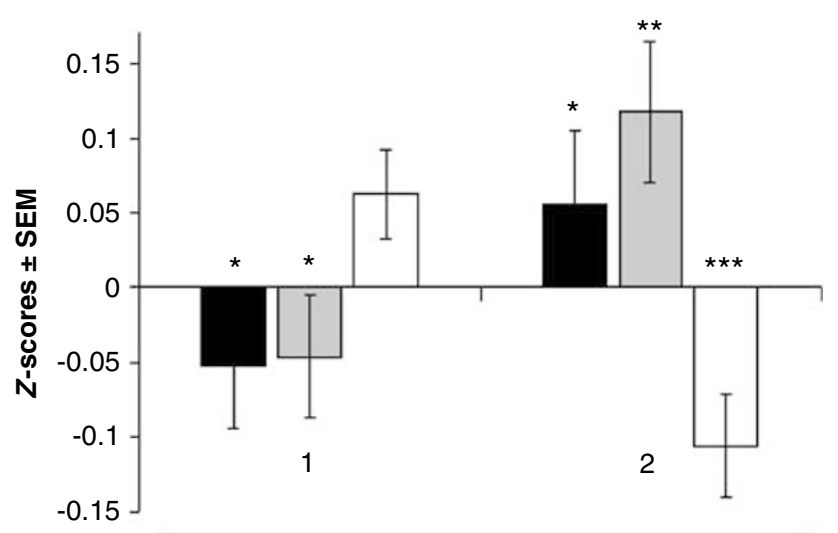

Depression $\square$ Neuroticism $\square$ Agreeableness

Figure 2 Effects of haplotype I (A,T,T,T,G,G,A,T,C,T; population frequency: 18.34\%) and haplotype 2 (A,T,T,C,A,A,A,T,T,C; population frequency: 15.27\%) on depression, neuroticism, and agreeableness scores. Z-scores were calculated as follows: (haplotype mean score-total population mean)/SD of haplotype mean. SEM: standard error of mean. Significant haplotypic effects: $* p<0.05, * * p<0.005$, $* * * * 0.000$ I.

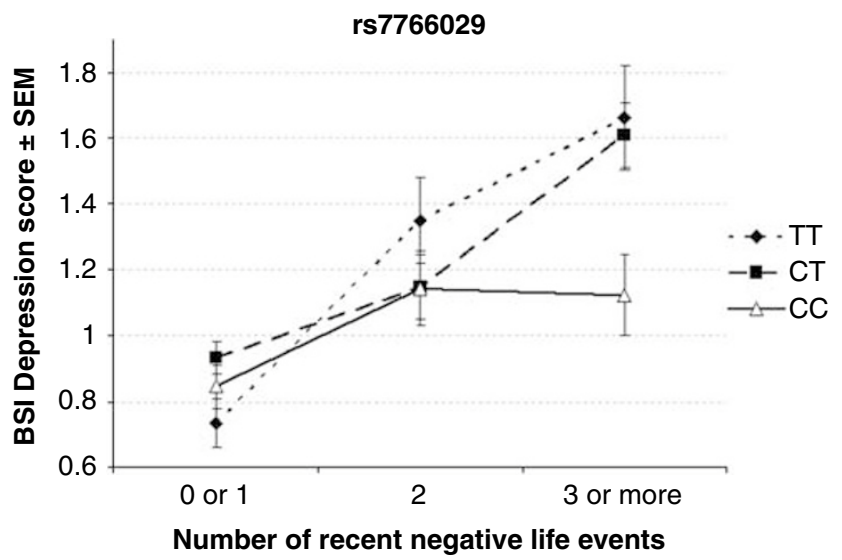

Figure 3 Significant interaction between rs7766029 and recent negative life events on depression scores ( $p_{\text {add }}=0.0004, p_{\text {rec }}=0.0007$, after false discovery rate (FDR) correction for multiple testing $q_{\text {add }}=0.004$, $\left.q_{\text {rec }}=0.004\right)$. Age, sex, and recent negative life events were covariates in this calculation. T allele carriers are more vulnerable to negative life events than CC genotype carriers (numbers in subgroups according to negative life events and genotype: 0 or $1: \Pi T=174, C T=387, C C=207 ; 2: \Pi T=54$, $C T=96, C C=72$; and 3 or more: $T T=37, C T=97, C C=60$.).

survive FDR correction (for detailed results, see Supplementary Table S4).

Finally, we used childhood adversity scores as covariates in the haplotypic trend regression. Haplotypic association between the CNR1 gene and depression scores became more significant (explained variance $1.1 \%, p=0.012$, permutated $p=0.012$, FDR $q=0.007$; Table 3 ), suggesting that childhood adversity acts independently from the CNR1 gene. This model remained significant after reintroducing recent negative life events scores into it (explained variance $1.0 \%, p=0.035$, permutated $p=0.029$, FDR $q=0.013)$. Failure to include childhood adversity in variance models could be an important confounding variable in association studies of CNR1 and possibly other genes in depression.

\section{DISCUSSION}

This is the first study to demonstrate a significant association between the CNR1 gene and a high neuroticism/low agreeableness phenotype. Haplotype had a statistically significant effect on neuroticism and agreeableness, although single markers showed only weak associations. This observation directed our interests toward interactions between SNPs. Using epistasis calculations on agreeableness and neuroticism, we observed interaction between SNPs located at the $5^{\prime}$ end and SNPs in the second haploblock. Previously, Zhang et al (2004) demonstrated that combinations of rs806379, rs1535255, and rs2023239 influenced the transcription of the CNR1 gene. Furthermore, in our study, we found that the same haploblock 1 variation (ATT in haplotypes 1 and 2) showed an opposite effect on agreeableness, neuroticism, and depression depending on the variation in haploblock 2 (haplotype 1: TGGATCT and haplotype 2: CAAATTC).

Our data emphasize the point that although separate SNPs probably explain less than $1 \%$ variance in these phenotypes (Flint et al, 2008; Shifman et al, 2008), genetic risk factors can be revealed in gene $\times$ gene or gen$\mathrm{e} \times$ environment interactions. Shifman et al (2008) in a recent whole genome association study failed to find a susceptibility locus for neuroticism in the CNR1 genetic region but they had only a $50 \%$ power to detect loci accounting for $1 \%$ of the variance. Furthermore, based on HapMap CEU data set, the SNPs covering this region using Affymetrix $500 \mathrm{~K}$ mapping arrays are in low LD with the SNPs in our study (we found only one common SNP: rs806369).

Depression symptom scores showed significant association with the CNR1 gene after controlling for the effect of childhood adversity. This observation suggests that the CNR1 gene does not modify the influence of early trauma on current levels of depression. In contrast, the CNR1 gene significantly interacted with negative life events over the past 12 months in explaining depression scores. On the basis of this result, we propose that the CNR1 gene modifies the depressive effect of experienced negative life events in humans, which parallels the finding that $\mathrm{CB} 1-/-$ mice are more sensitive than wild-type controls to 4 weeks of chronic mild unpredictable stress in triggering learned helplessness and anhedonia (Martin et al, 2002; Valverde et al, 2005; Gorzalka et al, 2008).

Neuroticism can be defined as the ease with which emotions are aroused. It is a well-known predictor for lifetime depression and acts by magnifying the triggering effect of life events on the onset of depression (Kendler et al, 2004 ). About $50 \%$ of the genetic vulnerability to depression is shared with genetic risk factors for neuroticism (Kendler et al, 2006). Hitherto, the main identified genetic influence is the short-long polymorphism in the promoter region of the serotonin transporter gene (5HTTLPR) (Lesch, 2004). The less active short allele of the 5HTTLPR is associated with higher neuroticism (Greenberg et al, 2000) and it affects both the structure and function of an endophenotypic corticolimbic circuit underpinning emotion regulation (Hariri et al, 2006). Although the 5HTTLPR polymorphism accounts for only a few percent of the variation in neuroticism, it nevertheless shares the characteristic of 
increasing sensitivity to life events in triggering depression (Caspi et al, 2003; Jacobs et al, 2006; Uher and McGuffin, 2008; Lazary et al, 2008). The fact that CNR1 variants are not only associated with neuroticism but also interact with recent life events to predict current depressive symptoms suggests the variants act on the core endophenotypic emotion regulation processes of neuroticism.

Neuroticism has been shown to be a strong risk factor also for anxiety (Bienvenu et al, 2004; Kendler et al, 2007). In our study, we could not demonstrate significant effect of the CNR1 gene on anxiety symptoms, although both human (Christensen et al, 2007) and animal (Haller et al, 2004a, b) data suggest that impaired CB1 receptor signaling induces anxiety. This negative result raises the possibility that interaction with other genes or environmental factors is necessary for the anxiogenic effect of the CB1 gene. Indeed, CB1-I- animals showed state-dependent increase of anxiety: they behaved similarly to the wild-type animals in non-/mildly stressful paradigms in contrast to the acute highly stressful paradigms where anxiety symptoms markedly increased compared with wild-type animals (Haller et al, 2004a). Further studies are needed to test CNR1 gene $\times$ gene and CNR 1 gene $\times$ environment interactions in humans.

Much less is known about the role of agreeableness in depression. In general, people who score highly for agreeableness (reflecting a prosocial cooperative nature) are more likely to cope by seeking support and using less confrontation (O'Brien and DeLongis, 1996). Most studies investigating the role of personality in depression have not reported any major effects of agreeableness (Bienvenu et al, 2004; Kendler et al, 2006). However, indirect evidence suggests that lower agreeableness predicts the development of depression in various patient groups including adolescents who suffered severe burns in early childhood (Liber et al, 2008), adults undergoing interferon-alpha treatment for hepatitis C (Lotrich et al, 2007), and patients with chronic kidney disease (Hoth et al, 2007). Finch and Graziano (2001) demonstrated that agreeableness exerts its effects on depression exclusively through social exchange such as social support and social conflict. In $\mathrm{CB} 1-/-$ animals, social contacts were reduced in the social interaction test (Haller et al, 2004a) and this is usually taken as an index of anxiety, but could indicate a lack of response to social reinforcement that might underpin the association between agreeableness and CNR1 gene variations. Furthermore, although infrequently cited, the 5HTTLPR short allele has also been associated with lower agreeableness (Greenberg et al, 2000). Therefore, it is possible that a high neuroticism/low agreeableness phenotype has a stronger predictive value for genetic vulnerability to depression than neuroticism alone. Further studies are needed to explore this hypothesis.

High neuroticism and low agreeableness are also risk factors for several other psychiatric conditions that are frequently co-morbid with depression. Independent of the clusters, high neuroticism and low agreeableness were consistent dimensional characteristics of personality disorders in young adults (Moran et al, 2006). Substance use disorders, especially smoking (Terracciano and Costa, 2004), alcohol (Malouff et al, 2007), marijuana (Terracciano et al, 2008), and polysubstance abuse (McCormick et al,
1998) have also been associated with a high neuroticism/low agreeableness phenotype. The CNR1 gene has been associated with substance use disorders (Zhang et al, 2004; Zuo et al, 2007) and this association might be driven by the common personality structure influenced by this gene, as we have demonstrated in this study. Another study did not find association between substance use and CNR1 gene, but they investigated only a limited part of the CNR1 gene (Herman et al, 2006). We found a significant interaction to exist between the two haploblocks of this gene (epistasis), and this may have an impact on the expression of CB1 receptor (Zhang et al, 2004). Schizophrenia has also been associated with the CNR1 gene, although with conflicting results (Levinson et al, 2000; Leroy et al, 2001; Zhang et al, 2004; Chavarria-Siles et al, 2008; Hamdani et al, 2008). It is important to note that schizophrenic patients compared with depressed subjects, score just as high for neuroticism but even lower for agreeableness (Bagby et al, 1997), particularly if they have co-morbid substance abuse disorder (Reno, 2004).

In conclusion, our results provide evidence that CNR1 gene is implicated in determining a personality phenotype (high neuroticism and low agreeableness), which has been associated with, and may be a vulnerability factor for, a variety of psychiatric conditions, including major depression and substance misuse. In addition, our finding that current depressive symptoms can be partly explained by an interaction between recent life events and variation in the CNR1 gene is further support for the eCB system playing a role in the development of depressive symptoms. Further studies are needed to evaluate the mechanism by which CNR1 gene expression and translation are controlled.

\section{ACKNOWLEDGEMENTS}

We are grateful to Heaton Mersey Medical Practice and Cheadle Medical Practice for their assistance in the recruitment. This study was supported by the Sixth Framework Program of the EU, NewMood, LSHM-CT2004-503474.

\section{DISCLOSURE/CONFLICT OF INTEREST}

The authors declare that, except for income received from their primary employer, no financial support or compensation has been received from any individual or corporate entity over the past 3 years for research or professional service and there are no personal financial holdings that could be perceived as constituting a potential conflict of interest.

\section{REFERENCES}

Ashton CH, Moore PB, Gallagher P, Young AH (2005). Cannabinoids in bipolar affective disorder: a review and discussion of their therapeutic potential. J Psychopharmacol 19: 293-300.

Bagby RM, Bindseil KD, Schuller DR, Rector NA, Young LT, Cooke RG et al (1997). Relationship between the Five-Factor Model of personality and unipolar, bipolar and schizophrenic patients. Psychiatry Res 70: 83-94.

Barrero FJ, Ampuero I, Morales B, Vives F, de Dios Luna Del Castillo J, Hoenicka J et al (2005). Depression in Parkinson's 
disease is related to a genetic polymorphism of the cannabinoid receptor gene (CNR1). Pharmacogenomics J 5: 135-141.

Barrett JC, Fry B, Maller J, Daly MJ (2005). Haploview: analysis and visualization of LD and haplotype maps. Bioinformatics 21: 263-265.

Bernstein DP, Fink L, Handelsman L, Foote J, Lovejoy M, Wenzel K et al (1994). Initial reliability and validity of a new retrospective measure of child abuse and neglect. Am J Psychiatry 151: $1132-1136$.

Bienvenu OJ, Samuels JF, Costa PT, Reti IM, Eaton WW, Nestadt G (2004). Anxiety and depressive disorders and the Five-Factor Model of personality: a higher- and lower-order personality trait investigation in a community sample. Depress Anxiety 20: 92-97.

Bouchard Jr TJ, McGue M (2003). Genetic and environmental influences on human psychological differences. J Neurobiol 54: 4-45.

Brugha T, Bebbington P, Tennant C, Hurry J (1985). The list of threatening experiences: a subset of 12 life event categories with considerable long-term contextual threat. Psychol Med 15: 189-194.

Caspi A, Sugden K, Moffitt TE, Taylor A, Craig IW, Harrington H et al (2003). Influence of life stress on depression: moderation by a polymorphism in the 5-HTT gene. Science 301: 386-389.

Chakrabarti B, Kent L, Suckling J, Bullmore E, Baron-Cohen S (2006). Variations in the human cannabinoid receptor (CNR1) gene modulate striatal responses to happy faces. Eur J Neurosci 23: $1944-1948$.

Chavarria-Siles I, Contreras-Rojas J, Hare E, Walss-Bass C, Quezada P, Dassori A et al (2008). Cannabinoid receptor 1 gene (CNR1) and susceptibility to a quantitative phenotype for hebephrenic schizophrenia. Am J Med Genet B Neuropsychiatr Genet 147B: 279-284.

Chen X, Williamson VS, An SS, Hettema JM, Aggen SH, Neale MC et al (2008). Cannabinoid receptor 1 gene association with nicotine dependence. Arch Gen Psychiatry 65: 816-824.

Christensen R, Kristensen PK, Bartels EM, Bliddal H, Astrup A (2007). Efficacy and safety of the weight-loss drug rimonabant: a meta-analysis of randomised trials. Lancet 370: 1706-1713.

Costa Jr PT, McCrae RR (1992). Revised NEO Personality Inventory (NEO-PI-R) and NEO Five-Factor Inventory (NEO-FFI) Professional Manual. Psychological Assessment Resources: Odessa, FL.

Derogatis L (1993). BSI: Brief Symptom Inventory: Administration, Scoring, and Procedures Manual. National Computer Systems Pearson Inc.: Minneapolis.

Domschke K, Dannlowski U, Ohrmann P, Lawford B, Bauer J, Kugel $\mathrm{H}$ et al (2008). Cannabinoid receptor 1 (CNR1) gene: impact on antidepressant treatment response and emotion processing in major depression. Eur Neuropsychopharmacol 18: 751-759.

Ehlers CL, Slutske WS, Lind PA, Wilhelmsen KC (2007). Association between single nucleotide polymorphisms in the cannabinoid receptor gene (CNR1) and impulsivity in southwest California Indians. Twin Res Hum Genet 10: 805-811.

Fanous AH, Kendler KS (2005). Genetic heterogeneity, modifier genes, and quantitative phenotypes in psychiatric illness: searching for a framework. Mol Psychiatry 10: 6-13.

Finch JF, Graziano WG (2001). Predicting depression from temperament, personality, and patterns of social relations. J Pers 69: 27-55.

Flint J, Shifman S, Munafo M, Mott R (2008). Genetic variants in major depression. Novartis Found Symp 289: 23-32.

Freeman B, Smith N, Curtis C, Huckett L, Mill J, Craig IW (2003). DNA from buccal swabs recruited by mail: evaluation of storage effects on long-term stability and suitability for multiplex polymerase chain reaction genotyping. Behav Genet 33: 67-72.

Gabriel SB, Schaffner SF, Nguyen H, Moore JM, Roy J, Blumenstiel $B$ et al (2002). The structure of haplotype blocks in the human genome. Science 296: 2225-2229.
Gorzalka BB, Hill MN, Hillard CJ (2008). Regulation of endocannabinoid signaling by stress: implications for stress-related affective disorders. Neurosci Biobehav Rev 32: 1152-1160.

Greenberg BD, Li Q, Lucas FR, Hu S, Sirota LA, Benjamin J et al (2000). Association between the serotonin transporter promoter polymorphism and personality traits in a primarily female population sample. Am J Med Genet 96: 202-216.

Hall W, Solowij N (1998). Adverse effects of cannabis. Lancet 352: 1611-1616.

Haller J, Varga B, Ledent C, Barna I, Freund TF (2004a). Contextdependent effects of CB1 cannabinoid gene disruption on anxiety-like and social behaviour in mice. Eur J Neurosci 19: 1906-1912.

Haller J, Varga B, Ledent C, Freund TF (2004b). CB1 cannabinoid receptors mediate anxiolytic effects: convergent genetic and pharmacological evidence with CB1-specific agents. Behav Pharmacol 15: 299-304.

Hamdani N, Tabeze JP, Ramoz N, Ades J, Hamon M, Sarfati Y et al (2008). The CNR1 gene as a pharmacogenetic factor for antipsychotics rather than a susceptibility gene for schizophrenia. Eur Neuropsychopharmacol 18: 34-40.

Hariri AR, Drabant EM, Weinberger DR (2006). Imaging genetics: perspectives from studies of genetically driven variation in serotonin function and corticolimbic affective processing. Biol Psychiatry 59: 888-897.

Herman AI, Kranzler HR, Cubells JF, Gelernter J, Covault J (2006). Association study of the CNR1 gene exon 3 alternative promoter region polymorphisms and substance dependence. Am J Med Genet B Neuropsychiatr Genet 141: 499-503.

Hill MN, Gorzalka BB (2005a). Is there a role for the endocannabinoid system in the etiology and treatment of melancholic depression? Behav Pharmacol 16: 333-352.

Hill MN, Gorzalka BB (2005b). Pharmacological enhancement of cannabinoid CB1 receptor activity elicits an antidepressant-like response in the rat forced swim test. Eur Neuropsychopharmacol 15: 593-599.

Hinds DA, Stuve LL, Nilsen GB, Halperin E, Eskin E, Ballinger DG et al (2005). Whole-genome patterns of common DNA variation in three human populations. Science 307: 1072-1079.

Hoth KF, Christensen AJ, Ehlers SL, Raichle KA, Lawton WJ (2007). A longitudinal examination of social support, agreeableness and depressive symptoms in chronic kidney disease. J Behav Med 30: 69-76.

Jacobs N, Kenis G, Peeters F, Derom C, Vlietinck R, van Os J (2006). Stress-related negative affectivity and genetically altered serotonin transporter function: evidence of synergism in shaping risk of depression. Arch Gen Psychiatry 63: 989-996.

John OP, Srivastava S (1999). The Big Five trait taxonomy: history, measurement, and theoretical perspectives. In: Pervin LA, John OP (eds). Handbook of Personality: Theory and Research 2nd edn Guilford Press: New York. pp 102-139.

Kendler KS, Gardner CO, Gatz M, Pedersen NL (2007). The sources of co-morbidity between major depression and generalized anxiety disorder in a Swedish national twin sample. Psychol Med 37: 453-462.

Kendler KS, Gatz M, Gardner CO, Pedersen NL (2006). Personality and major depression: a Swedish longitudinal, population-based twin study. Arch Gen Psychiatry 63: 1113-1120.

Kendler KS, Kuhn J, Prescott CA (2004). The interrelationship of neuroticism, sex, and stressful life events in the prediction of episodes of major depression. Am J Psychiatry 161: 631-636.

Khan AA, Jacobson KC, Gardner CO, Prescott CA, Kendler KS (2005). Personality and comorbidity of common psychiatric disorders. Br J Psychiatry 186: 190-196.

Lazary J, Lazary A, Gonda X, Benko A, Molnar E, Juhasz G et al (2008). New evidence for the association of the serotonin transporter gene (SLC6A4) haplotypes, threatening life events, and depressive phenotype. Biol Psychiatry 64: 498-504. 
Leroy S, Griffon N, Bourdel MC, Olie JP, Poirier MF, Krebs MO (2001). Schizophrenia and the cannabinoid receptor type 1 (CB1): association study using a single-base polymorphism in coding exon 1. Am J Med Genet 105: 749-752.

Lesch KP (2004). Gene-environment interaction and the genetics of depression. J Psychiatry Neurosci 29: 174-184.

Levinson DF, Holmans P, Straub RE, Owen MJ, Wildenauer DB, Gejman PV et al (2000). Multicenter linkage study of schizophrenia candidate regions on chromosomes 5q, 6q, 10p, and 13q: schizophrenia linkage collaborative group III. Am J Hum Genet 67: 652-663.

Liber JM, Faber AW, Treffers PD, Van Loey NE (2008). Coping style, personality and adolescent adjustment 10 years post-burn. Burns 34: 775-782.

Lotrich FE, Rabinovitz M, Gironda P, Pollock BG (2007). Depression following pegylated interferon-alpha: characteristics and vulnerability. J Psychosom Res 63: 131-135.

Malouff JM, Thorsteinsson EB, Rooke SE, Schutte NS (2007). Alcohol involvement and the Five-Factor Model of personality: a meta-analysis. J Drug Educ 37: 277-294.

Martin M, Ledent C, Parmentier M, Maldonado R, Valverde O (2002). Involvement of CB1 cannabinoid receptors in emotional behaviour. Psychopharmacology (Berl) 159: 379-387.

McCormick RA, Dowd ET, Quirk S, Zegarra JH (1998). The relationship of NEO-PI performance to coping styles, patterns of use, and triggers for use among substance abusers. Addict Behav 23: 497-507.

McGue M, Bouchard Jr TJ (1998). Genetic and environmental influences on human behavioral differences. Annu Rev Neurosci 21: $1-24$.

Montgomery SA, Asberg M (1979). A new depression scale designed to be sensitive to change. Br J Psychiatry 134: 382-389.

Moran P, Coffey C, Mann A, Carlin JB, Patton GC (2006). Dimensional characteristics of DSM-IV personality disorders in a large epidemiological sample. Acta Psychiatr Scand 113: 233-236.

O'Brien TB, DeLongis A (1996). The interactional context of problem-, emotion-, and relationship-focused coping: the role of the Big Five personality factors. J Pers 64: 775-813.

Reno RM (2004). Personality characterizations of outpatients with schizophrenia, schizophrenia with substance abuse, and primary substance abuse. J Nerv Ment Dis 192: 672-681.

Serra G, Fratta W (2007). A possible role for the endocannabinoid system in the neurobiology of depression. Clin Pract Epidemol Ment Health 3: 25.
Shifman S, Bhomra A, Smiley S, Wray NR, James MR, Martin NG et al (2008). A whole genome association study of neuroticism using DNA pooling. Mol Psychiatry 13: 302-312.

Snaith RP, Baugh SJ, Clayden AD, Husain A, Sipple MA (1982). The Clinical Anxiety Scale: an instrument derived from the Hamilton Anxiety Scale. Br J Psychiatry 141: 518-523.

Storey JD, Tibshirani R (2003). Statistical significance for genomewide studies. Proc Natl Acad Sci USA 100: 9440-9445.

Terracciano A, Costa Jr PT (2004). Smoking and the Five-Factor Model of personality. Addiction 99: 472-481.

Terracciano A, Lockenhoff CE, Crum RM, Bienvenu OJ, Costa Jr PT (2008). Five-Factor Model personality profiles of drug users. BMC Psychiatry 8: 22.

Tsai SJ, Wang YC, Hong CJ (2001). Association study between cannabinoid receptor gene (CNR1) and pathogenesis and psychotic symptoms of mood disorders. Am J Med Genet 105: 219-221.

Uher R, McGuffin P (2008). The moderation by the serotonin transporter gene of environmental adversity in the aetiology of mental illness: review and methodological analysis. Mol Psychiatry 13: 131-146.

Valverde O, Karsak M, Zimmer A (2005). Analysis of the endocannabinoid system by using $\mathrm{CB} 1$ cannabinoid receptor knockout mice. Handb Exp Pharmacol 168: 117-145.

Vinod KY, Hungund BL (2006). Role of the endocannabinoid system in depression and suicide. Trends Pharmacol Sci 27: 539-545.

Westfall FH, Young SS (1993). Resampling-Based Multiple Testing: Examples and Methods for P-value Adjustment. Wiley: New York.

Widiger TA, Sankis LM (2000). Adult psychopathology: issues and controversies. Annu Rev Psychol 51: 377-404.

Witkin JM, Tzavara ET, Davis RJ, Li X, Nomikos GG (2005). A therapeutic role for cannabinoid CB1 receptor antagonists in major depressive disorders. Trends Pharmacol Sci 26: 609-617.

Zhang PW, Ishiguro $\mathrm{H}$, Ohtsuki $\mathrm{T}$, Hess $\mathrm{J}$, Carillo $\mathrm{F}$, Walther D et al (2004). Human cannabinoid receptor 1: $5^{\prime}$ exons, candidate regulatory regions, polymorphisms, haplotypes and association with polysubstance abuse. Mol Psychiatry 9: 916-931.

Zuo L, Kranzler HR, Luo X, Covault J, Gelernter J (2007). CNR1 variation modulates risk for drug and alcohol dependence. Biol Psychiatry 62: 616-626.

Supplementary Information accompanies the paper on the Neuropsychopharmacology website (http://www.nature.com/npp) 